\title{
CONFIGURAÇÕES NA FRONTEIRA ENTRE BRASIL/PARAGUAI E A ORGANIZAÇÃO DO PROGRAMA ESCOLAS INTERCULTURAIS DE FRONTEIRA (PEIF)
}

\author{
CONFIGURACIONES EN LA FRONTERA ENTRE BRASIL / PARAGUAY Y LA \\ ORGANIZACIÓN DEL PROGRAMA ESCUELAS INTERCULTURALES DE \\ FRONTERA (PEIF)
}

\section{CONFIGURATIONS AT THE BORDER BETWEEN BRAZIL / PARAGUAY AND THE ORGANIZATION OF THE INTERCULTURAL BORDER SCHOOLS PROGRAM}

(PEIF)

RESUMO: Este artigo objetiva analisar o PEIF como uma política supranacional de formação de professores na fronteira do Brasil com o Paraguai a partir da configuração executada na região sul do Mato Grosso do Sul. Estabelece o seguinte problema de pesquisa: o PEIF apresentou contribuição significativa para a realidade educacional na fronteira do Brasil com o Paraguai? Em termos metodológicos este estudo ancora-se na pesquisa documental, qualitativa e de análise de conteúdo, coletadas da tese de doutorado em andamento sobre o tema. Constatou-se nesta pesquisa que o PEIF como uma política específica para a região de fronteira buscou na formação de professores meios de solidificar a integração regional no âmbito do Mercosul.

PALAVRAS-CHAVE: Política educacional. Formação de professores. Fronteira.

RESUMEN: Este artículo tiene como objetivo analizar el PEIF como una política supranacional de formación de profesores en la frontera de Brasil con Paraguay a partir de la configuración ejecutada en la región sur de Mato Grosso do Sul. Y establece el siguiente problema de investigación: El PEIF presentó una contribución significativa para la realidad educativa en la frontera de Brasil con Paraguay? En términos metodológicos este estudio se ancla en la investigación documental, cualitativa y de análisis de contenido recogidas de la tesis de doctorado en marcha sobre el tema. Se constató en esta investigación que el PEIF como una política específica para la región de frontera buscó en la formación de profesores medios de solidificar la integración regional en el ámbito del Mercosur.

PALABRAS CLAVE: Política educativa. Formación de profesores. Frontera.

ABSTRACT: This article aims to analyze PEIF as a supranational policy of teacher training on the border of Brazil and Paraguay from the configuration carried out in the southern region

${ }^{1}$ Universidade Federal de Mato Grosso do Sul (UFMS), Ponta Porã - MS - Brasil. Docente da Faculdade de Educação da UFMS. Mestre e Doutora pelo Programa de Pós-Graduação em Educação/Faculdade de Educação/Universidade Federal da Grande Dourados - UFGD/Dourados - Brasil. Graduada em Pedagogia. ORCID: https://orcid.org/0000-0002-5785-972>. E-mail: mara.marques@ufms.br 
of Mato Grosso do Sul. It establishes the following research problem: the educational reality on the border of Brazil and Paraguay? In methodological terms this study is anchored in the documentary, qualitative and content analysis collected from the doctoral thesis in progress on the subject. It was verified in this research that the PEIF as a specific policy for the border region sought in the training of teachers means of solidifying the regional integration in the scope of Mercosur.

KEYWORDS: Educational policy. Teacher training. Border.

\section{Introdução}

A fronteira entre Brasil e Paraguai, historicamente, é marcada pela disputa territorial que levou à Guerra do Paraguai (1864-1870), que foi o maior conflito armado internacional ocorrido na América do Sul no século XIX, no qual os paraguaios saíram derrotados. O pósGuerra levou o Paraguai a um enfraquecimento competitivo ao longo do período: a derrocada paraguaia teve seus reflexos principalmente na economia e na política perante os demais países sul-americanos.

O Brasil adotou na década de 1990 um regime democrático, com o sancionamento da CF em 1988 e as reformas, bem como a evolução das políticas educacionais; o Paraguai viveu quatro décadas de regime fechado ao pluralismo de ideias e liberdade de expressão (ditadura) (RIVAROLA, 2008).

Neste contexto, o processo de integração regional representou uma oportunidade para alavancar a economia dos países da América Latina, um elemento importante para justificar a circulação de pessoas, bens e serviços, além de construir um espaço regional integrado no subcontinente (VIZENTINI, 2007). Dessa forma, a criação do Mercado Comum do Sul (MERCOSUL) em 1991, por meio da assinatura do Tratado de Assunção, tinha a intenção de promover o desenvolvimento econômico dos países membros, a princípio Argentina, Brasil, Paraguai e Uruguai, com a livre circulação de bens, serviços e fatores produtivos entre as nações.

A integração entre as nações transcendeu as vias econômicas e chegou à educação com a instauração no âmbito do Mercosul do Setor Educacional do Mercosul (SEM), o qual tinha a missão de integrar as nações por meio de ações que buscassem uma aproximação educacional entre países vizinhos.

É neste cenário incipiente que a pesquisa de tese de doutorado, que avalia os impactos do PEIF como uma política supranacional de formação para professores de fronteira. Este artigo 
representa uma parte do levantamento bibliográfico, documental (CELLARD, 2014), qualitativo (RICHARDSON, 2008) e de análise de conteúdo (BARDIN, 2016). Para tanto, este trabalho tem como questionamento central: o PEIF apresentou contribuição significativa para a realidade educacional na fronteira do Brasil com o Paraguai? Já o objetivo geral está em analisar o PEIF como uma política supranacional de formação de professores na fronteira do Brasil com o Paraguai a partir da configuração executada na região sul do Mato Grosso do Sul.

Para tanto, organizou-se a pesquisa em três momentos, sendo que na primeira parte buscou-se apresentar a realidade econômica e educacional do Brasil e do Paraguai com a finalidade de situar os leitores sobre o contexto em que a pesquisa se insere. No segundo momento apresentou-se o Programa Escolas Interculturais de Fronteira (PEIF) como uma proposta de formação intercultural de professores buscando a construção da identidade fronteiriça e a valorização das diferenças. Já no terceiro momento preocupou-se em trazer a configuração do PEIF na região sul do Mato Grosso do Sul objetivando contextualizar a realidade da pesquisa maior em andamento, e apontando alguns dos achados do estudo. Por fim, realizou-se as considerações do trabalho que apontam inconsistências no processo de integração regional por meio da educação.

\section{A realidade econômica e educacional do Brasil e do Paraguai}

A realidade brasileira perpassa por mudanças significativas, tanto no cenário político e econômico quanto educacional. As reformas educacionais, de acordo com Frigotto; Ciavata (2003), foram financiadas por organismos internacionais que trouxeram mudanças nas políticas para a educação, principalmente após o sancionamento da Constituição Federal de 1988, como explicita Cury (2002, p. 169):

A educação básica no Brasil ganhou contornos bastante complexos nos anos posteriores à Constituição Federal de 1988 e, sobretudo, nos últimos oito anos. Analisá-la não é fácil exatamente porque as contingências que a cercam são múltiplas e os fatores que a determinam têm sido objeto de leis, políticas e programas nacionais, alguns dos quais em convênio com órgãos internacionais.

À luz da realidade brasileira no setor educacional percebe-se que a influência internacional na concepção das políticas para a educação foi significativa. No cenário econômico, o Brasil possui uma renda média per capita de U\$323,46 por pessoa, um Produto Interno Bruto (PIB) em torno de U\$ 1,6 trilhão e uma população estimada em 209.146.437 
habitantes, segundo dados divulgados pelo Instituto Brasileiro de Geografia e Estatística (IBGE) em 2017. Outro fator relevante sobre o país recai sobre o desequilíbrio econômico apresentado pelo PIB entre 2008 e 2016, vivenciado conforme informações abaixo (valores em dólares):

Gráfico 1 - Escala de evolução do PIB do Brasil (1960-2017) - U\$

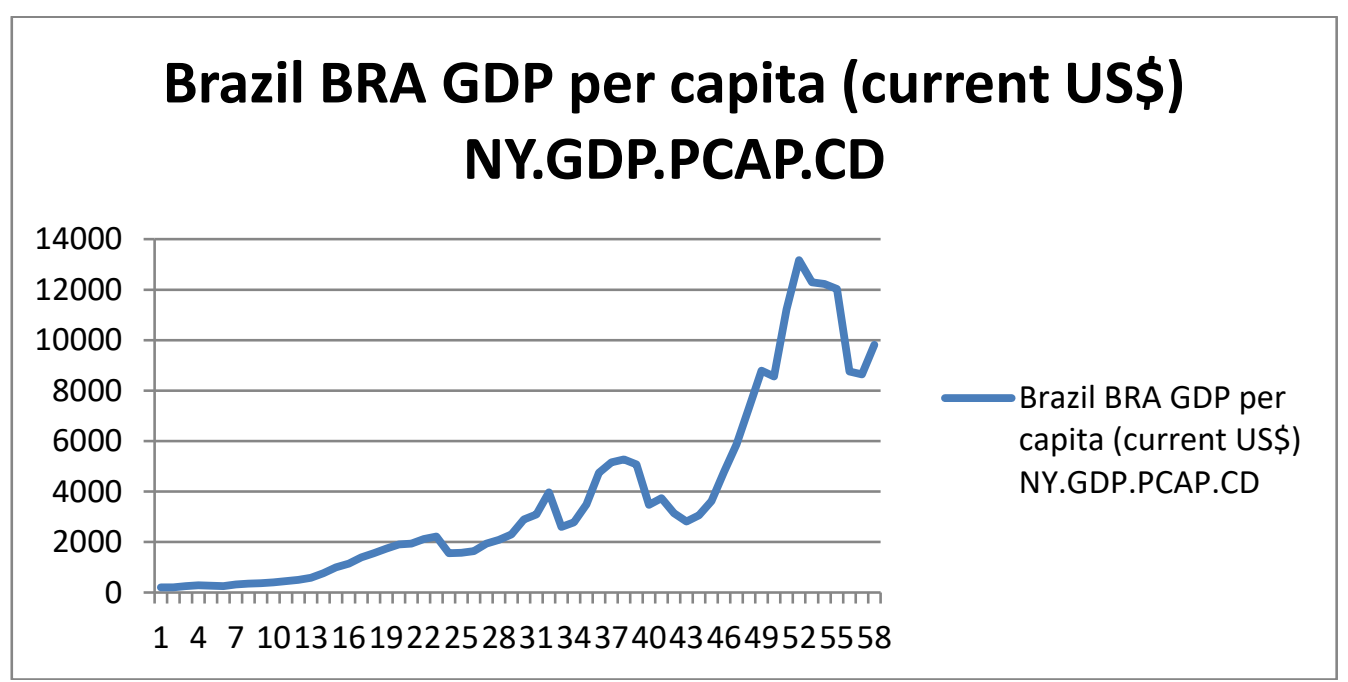

Fonte: The World Bank (https://data.worldbank.org/indicator/ny.gdp.pcap.cd).

A Gráfico 1 aponta que o Brasil apresentou um desenvolvimento expressivo entre os anos de 2009 a 2011, mas nos anos seguintes teve uma queda brusca do PIB, ficando entre U\$ 8.553.381 e U\$ 13.167.473, respectivamente. Já 2017 fechou com um PIB de U\$ 9.821.408, e houve reflexos desta estagnação em todas áreas, não apenas na economia. Na educação houve queda e cortes orçamentários nos investimentos, bem como nos programas educacionais. $\mathrm{O}$ PEIF, por exemplo, foi extinto em 2015 e não houve continuidade de ações em honra aos compromissos firmados no âmbito do Mercosul e do Setor Educacional do Mercosul (SEM).

Já o Paraguai passou por as reformas marcadas por influências no meio político e econômico que dificultaram o desenrolar das mudanças, deixando assim o país dentre os últimos a cumprir os acordos firmados em âmbito internacional, já que o país apresentava dificuldades em seu desenvolvimento e as demandas existentes na sociedade paraguaia exigiam cuidados (NIBUHR; ENNS, 1999).

De acordo com o Banco Mundial, o Paraguai apresentava uma população de cerca de 6,342 milhões de habitantes em 2009, tendo um PIB em 2016 de U\$ 27,44 bilhões e uma renda per capita de US\$ 9.400 em 2016. Vejamos o Gráfico 2, que aponta a ascensão de um país promissor economicamente na atualidade: 
Gráfico 2 - Escala de evolução do PIB do Paraguai (1960-2017) - U\$

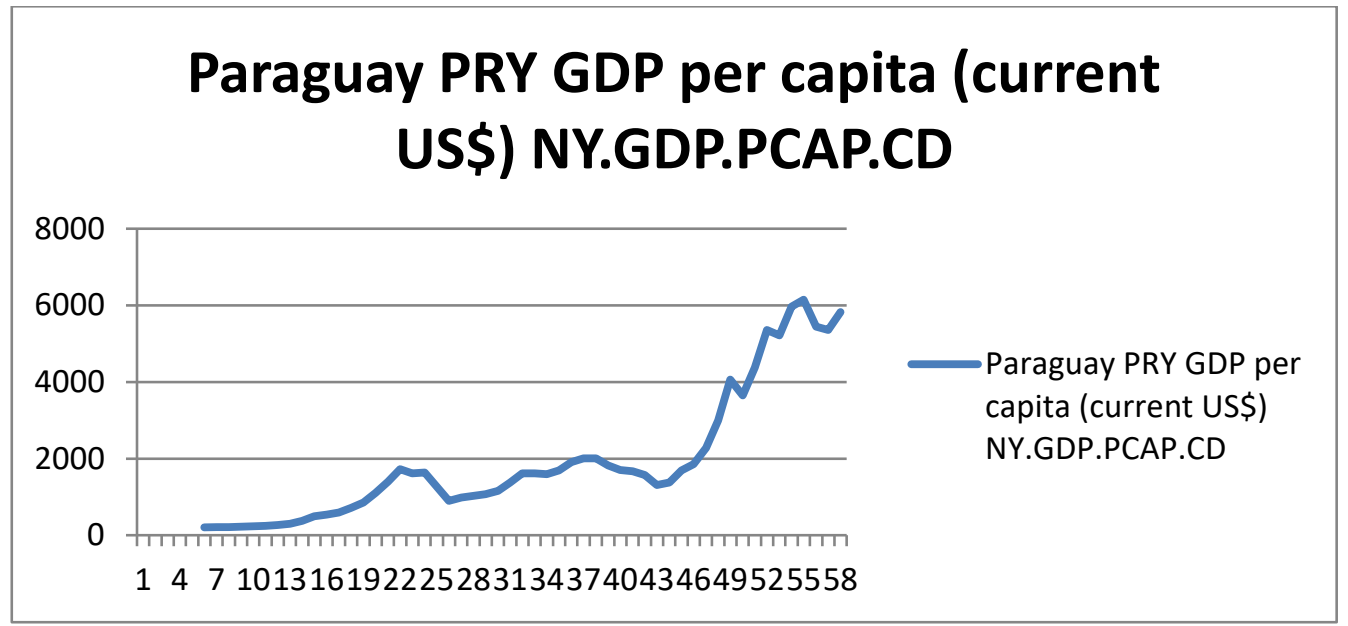

Fonte: The World Bank (https://data.worldbank.org/indicator/ny.gdp.pcap.cd)

O Gráfico 2 aponta o crescimento do PIB do Paraguai no período de doze anos, o que favorece o desenvolvimento econômico do país e a promissora recuperação do mesmo. No entanto, o Paraguai fechou 2017 com U\$ 5.823.766, PIB menor que o apresentado pelo Brasil. Apesar dos números discrepantes quanto ao contingente populacional e os rendimentos, o país busca melhorias na educação:

\begin{abstract}
A expansão da demanda, o crescimento da classe média, a reforma educativa que trouxe uma melhoria aos níveis educacionais da população, o processo de urbanização, a maior presença massiva dos meus de comunicação são fatores que estão mexendo com o elefante branco paraguaio, nada diferente do que apresentado inicialmente como questões comuns na América Latina (CASTRO, 2013. p. 72).
\end{abstract}

O Paraguai passou por um longo período de ditadura militar, mas com o fim do regime, em meados de 1989, houve um movimento de empoderamento da sociedade na busca por novos horizontes à nação, e foi neste período que os primeiros encaminhamentos para uma transição democrática ocorreram. Em 1994 iniciou-se o processo de reforma do sistema educacional paraguaio em meio a demandas globais de reorganização do capital e a constituição da democracia, já atendendo aos acordos firmados no âmbito do Mercosul e o SEM.

Neste contexto, de acordo com Rivarola (2000), constata-se que a educação paraguaia se apresenta com o menor desenvolvimento em todo continente e uma carência de base cultural para a promoção das mudanças necessárias para o setor avançar. Duarte (2011) salienta que o Paraguai, nesse período histórico da década de 1990, apresentava uma alta taxa de analfabetismo, pobreza generalizada e impotência por parte da população. 
Já em 1998 foi sancionada a Lei Geral da Educação Paraguaia, nº. 1.264, a qual respalda as reformas educativas dentro do sistema educacional nacional e propõe princípios para uma educação pública e privada, bem como concede à educação um lugar de destaque para a consolidação do regime democrático na nação. Essa tomada de decisão ocasionou a diminuição da desigualdade social e o surgimento de novas oportunidades para toda a população paraguaia. Vale ressaltar que esta Lei regulamenta os princípios de um sistema educacional considerando a educação de forma geral, a educação especial, o sistema escolar e suas modalidades de ensino (PARAGUAI, 1998).

Portanto, evidencia-se que a Lei $\mathrm{n}^{\mathrm{o}}$. 1.264/1998 representou um divisor de águas dentro do sistema educacional paraguaio, pois demarcou as diretrizes e bases da educação até então vigentes no país. Os documentos e compromissos firmados, deste período em diante, buscaram estar alinhados aos interesses do Mercosul e aos interesses dos organismos internacionais envolvidos. No quesito educação ambos os países realizaram investimentos para a efetivação de políticas educacionais, as quais foram fruto de compromissos firmados no âmbito do Mercosul e do SEM desde 2004, buscando a integração regional.

Conclui-se que ambos os países, Brasil e Paraguai, enfrentaram dificuldades e desafios nas políticas educacionais para honrarem os acordos fixados nas reuniões do Mercosul e do SEM. Contudo, mesmo em meio à realidade conturbada, estabeleceram leis que visavam trazer o direito à educação bilíngue a população de cada país. Na próxima seção apresentar-se-á o PEIF como um programa direcionado à formação continuada para professores e uma ação para a política de fronteira.

\section{O Programa Escolas Interculturais de Fronteira (PEIF)}

O PEIF tem em sua essência os princípios presentes, inicialmente, no Protocolo de Intenções firmado em 1991, o qual visava contribuir no setor educacional para alcançar objetivos políticos de integração no âmbito do Mercosul e, posteriormente, na Declaração de Brasíliaª firmada em 2003, bem como no Plano de Ação do Setor Educacional do Mercosul

2 A II Reunião de Presidentes Sul-Americanos realizada em Guayaquil no Equador em 26 e 27 de julho de 2002 simbolizou a continuidade de uma iniciativa diplomática brasileira na Cúpula Sul-Americana de Brasília, a qual ocorreu em 31 de agosto e $1^{\circ}$ de setembro de 2000. Assim, a reunião finalizou com a assinatura de duas declarações conjuntas, um referente ao estabelecimento de uma Zona de Paz Sul-Americana e outra relacionada à Integração, Segurança e Infraestrutura para o Desenvolvimento, a chamada "Declaração Conjunta de Brasília para o Fortalecimento da Integração Regional”. Esta Declaração tem por objetivo estabelecer um fórum com a finalidade de criar políticas coletivas de segurança e assim aprofundar a integração. Diante das dificuldades atuais para a discussão de novas rodadas de liberalização comercial, vê-se a criação de uma infraestrutura interligando a rede 
(SEM); por isso, as escolas da fronteira são intituladas escolas interculturais. Para tanto, todas as ações do Programa têm como foco o ensino bilíngue, no caso desta pesquisa, o Espanhol e a Língua Portuguesa.

O processo de integração regional entre países fronteiriços possibilita o estreitamento de laços econômicos, políticos, sociais e também educacionais entre países vizinhos, bem como viabiliza a implantação de políticas públicas de interesse comum entre os entes federativos (ANDRÉS, 2010; DRAIBE, 2007).

Lorenzoni (2013) salienta que o PEIF era custeado com recursos da Lei Orçamentária Anual (LOA) e com bolsas de pesquisa para os professores, bem como para os gestores das escolas participantes. A proposta de expansão do Programa a partir de 2014 tinha como prioridade a adesão das escolas participantes do Programa Mais Educação (PME) $)^{3}$ e Ensino Médio Inovador ${ }^{4}$, e por isso também escolas municipais passaram a integrar a formação. Torchi e Silva (2014) relatam que para a escola fronteiriça aderir ao programa se faz necessário uma inscrição on-line no sistema do MEC e, para isso, a escola deveria fazer parte do PME.

Quanto ao custeio para a execução do Programa nas escolas, Borges (2014) salienta que as escolas que aderiram ao Mais Educação receberam um recurso adicional do Programa Dinheiro Direto nas Escolas (PDDE), vinculado ao Fundo Nacional de Desenvolvimento da Educação (FNDE), subordinado ao MEC e à Universidade, no caso a UFGD, para promover a formação do PEIF e desenvolver ações que qualificassem a formação integral dos alunos no âmbito escolar.

Lorenzoni (2013) complementa que em 2012 onze municípios aderiram ao Programa em todo o Brasil, totalizando dezessete escolas com cerca de 7,5 mil alunos matriculados nos anos iniciais do ensino fundamental, público-alvo do Programa. Nesse universo, duzentos e cinquenta professores foram capacitados por dez universidades espalhadas pelo país. Já para 2014 o Programa ambicionava ampliar o atendimento para cento e oito escolas em 36

de transportes, comunicações e energia dos países sul-americanos como metas concretas para a integração física das economias. (VIZENTINI, 2007).

3 O Programa foi criado pela Portaria Interministerial $n^{\circ}$. 17/2007 e regulamentado pelo Decreto 7.083/10, representa uma estratégia do MEC para expandir a educação integral nas redes estaduais e municipais de ensino ampliando a jornada escolar para no mínimo 7 horas diárias, através da realização de atividades optativas nos macrocampos: acompanhamento pedagógico; educação ambiental; esporte e lazer; direitos humanos em educação; cultura e artes; cultura digital; promoção da saúde; comunicação e uso de mídias; investigação no campo das ciências da natureza e educação econômica.

${ }^{4}$ Foi instituído pela Portaria $n^{\circ} .971$, de 9 de outubro de 2009, no contexto da implementação das ações voltadas ao Plano de Desenvolvimento da Educação - PDE. O objetivo do Programa é apoiar e fortalecer os Sistemas de Ensino Estaduais e Distrital no desenvolvimento de propostas curriculares inovadoras nas escolas de Ensino Médio, disponibilizando apoio técnico e financeiro, consoante à disseminação da cultura de um currículo dinâmico, flexível, que atenda às expectativas e necessidades dos estudantes e às demandas da sociedade atual. 
municípios, envolvendo cerca de 2.100 professores sendo capacitados por quinze universidades (BORGES, 2014).

Trata-se de um Programa que buscou na parceria entre Ministério da Educação (MEC), por meio da Secretaria de Educação Básica (SEB), Universidades Federais, Secretarias Estaduais/Municipais de Educação e escolas fronteiriças, desenvolver ações de formação continuada para professores atuantes na fronteira. O PEIF foi instituído pela Portaria $\mathrm{n}^{\circ}$. 798/2012 e tem como objetivo, de acordo com o artigo $1^{\circ}$, contribuir para a formação integral do alunado, visando a integração regional por meio da educação intercultural nas escolas públicas de fronteira. Para tanto, o programa propõe mudanças no ambiente educativo, ou seja, almeja adequar o processo de ensino à realidade peculiar de fronteira com a ampliação da oferta de saberes, métodos, processos e conteúdos educacionais.

O PEIF previa, em sua estrutura organizacional, formações para os professores universitários, que seriam os multiplicadores em cada estado participante do Programa, capacitando-os a levar a formação continuada aos professores da educação básica de cada município que realizou a adesão ao PEIF. De acordo com a Portaria $n^{\circ}$. 798/2012, artigo $8^{\circ}$, cabe às Universidades capacitar os professores para atuar no Programa.

O PEIF propunha a realização de formação continuada com o intuito de sensibilizar o professor a desenvolver um modelo de ensino comum para a zona de fronteira (BRASIL, 2012) a partir da proposta da escola reflexiva (ALARCÃO, 2001), considerando a proposta metodológica da aprendizagem significativa (MOREIRA, 2013) e com o desenvolvimento do Ensino via Projetos de Aprendizagem (EPA), bem como os mapas conceituais (BRASIL, 2008). O PEIF busca instigar a escola e os professores a repensar suas práticas, trazendo o aluno para o centro do processo de educativo ${ }^{5}$.

Além das formações continuadas, os professores participantes do PEIF tinham que planejar suas aulas em parceria com os docentes do país vizinho para a realização do cruce (intercâmbio) entre professores, que representou uma possibilidade de despertar a curiosidade dos alunos sobre o outro país (BRASIL, 2008). Para Sturza (2014), o intercâmbio apresentava um significado relevante ao desenvolvimento intercultural da fronteira:

O "cruce" é a travessia, que em algumas fronteiras é a ponte; em outras, a balsa; em outra, apenas a rua. Mas cruzar, na dinâmica proposta para esse programa, é muito mais, pois coloca o professor no centro do processo à medida que é ele que leva a língua, a cultura e o conhecimento, mediando-os

${ }^{5} \mathrm{O}$ professor neste caso representa a figura de um "facilitador" do processo educativo do alunado, ou seja, o aluno torna-se um aprendiz, sendo considerado um sujeito na medida em que se autodetermina. Dessa forma, ganha o centro do processo de aprendizagem, como proposto pela lei francesa de 1989 (BOUTIN, 2017). 
com os alunos da escola parceira. O professor articula, planeja e desenvolve projetos em conjunto com o colega argentino, paraguaio, venezuelano e uruguaio. O "cruce" é o modo como se operacionaliza a principal ação da Escola Intercultural, baseada na troca dos docentes. Também se realizam atividades conjuntas de alunos, não em uma troca, mas em uma vivência linguística, cultural e social através de visitas, participações em eventos culturais, cívicos e esportivos (STURZA, 2014, p. 05).

Silva e Torchi (2016) evidenciam que no PEIF a diversidade cultural deve ser entendida e valorizada para que a comunidade escolar compreenda a riqueza da presença de uma segunda língua em seu cotidiano, seja a Língua Portuguesa para os paraguaios ou o Espanhol para os brasileiros. Assim, o trabalho com a interculturalidade torna-se relevante por respeitar as diferenças e promover encontros culturais.

Logo, o trabalho do PEIF deve perpassar a sala de aula e alcançar aspectos interculturais que necessitam ser desmistificados e encarados como uma realidade repleta de riquezas típicas de regiões fronteiriças, ou seja, sem preconceitos, pois a cultura presente na fronteira é peculiar ao restante de um país ao integrar dois povos distintos em um mesmo espaço.

Neste sentido, o trabalho intercultural proposto pelo PEIF propõe também o repensar do Projeto Político Pedagógico (PPP) da escola. Adequar-se à proposta do PEIF implica em promover alterações em todos os segmentos da escola, do gestor aos demais funcionários, sempre com a participação da comunidade escolar (FERNANDES, 2013).

Os PPPs das escolas, normalmente, atendem a um padrão estabelecido pelas Secretarias de Educação. O PEIF prevê o oposto desta prática, ou seja, há necessidade de discriminar a quantidade de alunos brasileiros e paraguaios, conforme salienta Oliveira (2015. p. 75): “Apesar da nomeação não definir a nacionalidade dos alunos como a anterior, ela confirma o contato, o vínculo familiar com o país vizinho", além de discriminar a proposta metodológica prevista no PEIF também no PPP.

Portanto, o PEIF em sua essência previa a parceria do MEC com as universidades, escolas, professores e alunos de fronteira para o desenvolvimento de uma formação continuada em que o professor fronteiriço tivesse a oportunidade de repensar sua prática e construir uma identidade intercultural. Na próxima seção tratar-se-á sobre a configuração do PEIF na região sul de Mato Grosso do Sul, apresentando a realidade do Programa nesta região de fronteira.

\section{A configuração do PEIF na região sul do Mato Grosso do Sul}


O PEIF na fronteira do Brasil com o Paraguai estabeleceu uma divisão de responsabilidades entre as duas Universidades Federais do MS, a Universidade Federal do Mato Grosso do Sul (UFMS) e Universidade Federal da Grande Dourados (UFGD), para a realização das formações continuadas para os professores das escolas participantes do PEIF. Abaixo se relacionam os municípios participantes da formação e as respectivas instituições formadoras:

Quadro 1 - Configuração do PEIF em Mato Grosso do Sul (2014)

\begin{tabular}{|llcc|}
\hline Município & Classificação & Países Fronteiriços & Universidade Formadora \\
\hline Amambai & Linha de Fronteira & Paraguai & UFGD \\
\hline Aral Moreira & Linha de Fronteira & Paraguai & UFGD \\
\hline Bela Vista & Cidade-Gêmea & Paraguai & UFMS \\
\hline Coronel Sapucaia & Linha de Fronteira & Paraguai & UFGD \\
\hline Corumbá & Cidade-Gêmea & Bolívia & UFMS \\
\hline Mundo Novo & Cidade-Gêmea & Paraguai & UFGD \\
\hline Paranhos & Cidade-Gêmea & Paraguai & UFGD \\
\hline Ponta Porã & Cidade-Gêmea & Paraguai & UFGD \\
\hline
\end{tabular}

Fonte: Assis (2016).

De acordo com Quadro 1, os municípios de Amambai, Aral Moreira, Coronel Sapucaia, Mundo Novo e Paranhos participaram do PEIF por serem consideradas cidades em faixa de fronteira (MATO GROSSO DO SUL, 2012), tendo como cidade-polo para a realização dos encontros da formação continuada a cidade de Ponta Porã, a qual faz fronteira com Pedro Juan Caballero/Paraguai.

Em 2012 ampliou-se a abrangência do Programa: além da fronteira entre Brasil e Paraguai, que já vinha ocorrendo desde 2009, agora houve a adesão da fronteira Brasil e Bolívia, precisamente em Corumbá-MS/Brasil e Puerto Quijarro/Bolívia, conforme expresso no Quadro 1. Nesta última localidade a formação continuada foi de responsabilidade da Universidade Federal de Mato Grosso do Sul, em parceria com o MEC e a Secretaria Municipal de Corumbá (MS) (ASSIS, 2016). Veja o quadro com as cidades participantes do PEIF sob responsabilidade da UFGD como unidade formadora e suas respectivas escolas participantes:

Quadro 2 - Participantes do PEIF sob a responsabilidade da UFGD

\begin{tabular}{|ll|}
\hline Municípios & \multicolumn{1}{c|}{ Escolas } \\
\hline Aral Moreira & Escola Municipal Adroaldo Da Cruz \\
\cline { 2 - 2 } & Escola Municipal Polo Indígena Arandu Renda Guarani Kaiowa \\
\hline Coronel Sapucaia & Escola Municipal Mauricio Rodrigues De Paula \\
\cline { 2 - 2 } & Escola Municipal Fernando De Souza Romanin \\
\cline { 2 - 2 } & Escola Municipal Ruy Espindola \\
\hline Mundo Novo & Escola Municipal Polo Carlos Chagas e Extensão José Honorato Da Silva \\
\hline Ponta Porã & Escola Estadual João Brembatti Calvoso \\
\cline { 2 - 2 } & Escola Municipal Polo Ignes Andreazza \\
\hline
\end{tabular}




\begin{tabular}{l} 
Escola Municipal Polo Joao Carlos Pinheiro Marques \\
\hline Escola Municipal Polo Rural Osvaldo de Almeida Matos \\
\hline Escola Municipal Polo Rural Graça De Deus \\
\hline Escola Municipal Polo Rural Nova Conquista \\
\hline Escola Municipal Polo Rural Juvenal Froes
\end{tabular}

Fonte: UFGD/PEIF (2014).

Cabe salientar que o PEIF na fronteira do Brasil com o Paraguai foi desenvolvido apenas em aspectos teóricos, sem a realização do cruce, ou seja, as escolas não alteraram suas metodologias e não realizaram intercâmbio com o país vizinho. A única escola que alterou seu PPP e aderiu ao EPA foi a Escola Estadual João Brembatti Calvoso. Para Borges (2014), por meio de formação continuada e do intercâmbio de professores buscava-se desenvolver um projeto pedagógico intercultural que tinha como ponto de partida a interculturalidade, tendo um currículo intercultural integral como foco.

Contudo, o foco do PEIF centrou-se na formação continuada de professores sem a realização do cruce, e esta realidade justifica-se pela saída do Paraguai do Mercosul em $2013^{6}$. Por este motivo não houve intercâmbio entre as escolas brasileiras e paraguaias, bem como o consequente desligamento do país do PEIF. Com a participação das escolas municipais em 2014, continuaram as formações para professores apenas entre as escolas brasileiras.

Sendo assim, o PEIF representou uma alternativa para os professores, que por meio da formação continuada, buscaram novas estratégias metodológicas para trabalhar de forma intercultural sem negligenciar a presença de um aluno paraguaio em uma sala de aula brasileira e nem desconsiderar a diversidade cultural presente na fronteira.

Para Torchi e Silva (2016), o Programa tem a preocupação em oferecer uma educação intercultural, baseada na cooperação fronteiriça. Dessa forma, permite ao aluno o acesso a oportunidades sociais, educacionais, culturais e econômicas de maneira a romper as limitações da língua, bem como o preconceito presente na fronteira.

Portanto, o PEIF apresenta-se como uma política supranacional que delineou uma proposta específica para a região de fronteira. E, apesar de não ser executado em sua integralidade, com mudanças na prática metodológica e realização do cruce nas escolas que participaram da formação continuada, trouxe novas perspectivas para se pensar a educação em região de fronteira.

${ }^{6}$ Em 22 de junho de 2012, o então Presidente paraguaio Fernando Lugo foi destituído de seu cargo. Desde o processo de impeachment, o Paraguai sofreu um processo de suspensão como membro do MERCOSUL. Após a suspensão do Paraguai, o MERCOSUL efetivou a entrada da Venezuela como membro permanente do bloco regional (FRIZZERA, 2013. p. 156). 


\section{Considerações finais}

O PEIF tinha como foco principal a formação continuada de professores, objetivando a promoção de um ensino pautado na realidade local, na construção da identidade fronteiriça e valorização da interculturalidade, bem como o multilinguismo presente nas escolas.

A execução do Programa delineou políticas educacionais específicas para a região de fronteira, representando uma evolução relevante ao estabelecer parceria entre MEC, Universidades, Secretarias de Educação tanto estaduais quanto municipais e escolas. Na região sul do MS, a UFGD ofereceu a formação para os professores das escolas, tendo o município de Ponta Porã como polo, com o envio de professores formadores semanalmente. O Programa propunha levar os professores à reflexão, conscientizando-os acerca da relevância da identidade fronteiriça em meio à interculturalidade presente na fronteira.

De acordo com a pesquisa, apenas a Escola Calvoso em Ponta Porã aderiu ao Programa ao realizar as alterações do PPP e desenvolver o EPA em sala de aula. Logo, o PEIF como uma política de formação continuada de professores não impactou a realidade entre Brasil e Paraguai, pois apenas uma escola de fato executou o Programa; as demais participaram das formações, mas sem realizar as alterações propostas.

Arrisca-se pontuar que a fronteira, por ser um espaço peculiar, apresenta de um lado um país, no caso o Paraguai, com sua cultura e histórico bilíngue (Espanhol e Guarani) assegurado em lei, e por outro lado o Brasil, com suas limitações linguísticas, de país monolíngue, e essas duas realidades distintas se unem por uma fronteira seca, onde apenas uma rua separa os dois países. Nesse sentido, a descontinuidade do PEIF como uma política supranacional denota a falta de preocupação dos países envolvidos com o processo de integração regional.

\section{REFERÊNCIAS}

ALARCÃO, I. Escola Reflexiva e Nova Racionalidade. 4 ed. Artes Médicas, 2001.

ANDRÉS, A. A educação superior no setor educacional do Mercosul. Consultora Legislativa da Área XV. Educação, Cultura e Desporto. Dezembro/2010.

ASSIS, J. H. do. V. P. Veias abertas nas fronteiras internacionais do Brasil: percalços na efetivação da educação como um direito universal. International Studies on Law and Education. CEMOrOc-Feusp/IJI-Univ. do Porto. 22 jan/abr 2016.

BARDIN, L. Análise de conteúdo. Ed. rev. e amp. 3 reimp. São Paulo: Edições 70, 2016. 
BORGES. P. Programa Escolas Interculturais de Fronteira: uma proposta pedagógica intercultural. In: BRASIL, TV Escola. Salto para o Futuro. Escolas Interculturais de Fronteira. Ano XXIV - Boletim 1. Maio 2014.

BRASIL. Constituição da República Federativa do Brasil de 1988. Disponível em: http://www.planalto.gov.br/ccivil_03/constituicao/constituicao.htm. Acesso em: 05 set. 2018.

BRASIL. Portaria Normativa Interministerial $\mathbf{n}^{\mathbf{0}}$. 17, de 24 de abril de 2007. Institui o Programa Mais Educação, que visa fomentar a educação integral de crianças, adolescentes e jovens, por meio do apoio a atividades socioeducativas no contraturno escolar. Disponível em: http://portal.mec.gov.br/arquivos/pdf/mais_educacao.pdf. Acesso em: 25 jun. 2017.

BRASIL. Ministério da Educação. Ministerio de Educación, Ciencia y Tecnología. Escolas de Fronteira. Brasília e Buenos Aires, março de 2008. Disponível em:

http://portal.mec.gov.br/seb/arquivos/pdf/Escolafronteiras/doc_final.pdf. Acesso em: 04 set. 2017

BRASIL, Portaria n. 971, de 9 de outubro de 2009. Institui o Programa Ensino Médio Inovador. Disponível em:

http://educacaointegral.mec.gov.br/images/pdf/port_971_09102009.pdf. Acesso em: 01 dez. 2018

BRASIL, Decreto n. 7.083, de 27 de janeiro de 2010. Dispõe sobre o Programa Mais Educação. Disponível em: http://www.planalto.gov.br/ccivil_03/_ato20072010/2010/decreto/d7083.htm. Acesso em: 12 nov. 2018

BRASIL, Portaria n. 798, de 19 de junho de 2012. Institui o Programa Escolas Interculturais de Fronteira, que visa a promover a integração regional por meio da educação intercultural e bilíngue.

BOUTIN, G. A relação entre professor-aluno no centro do processo educativo. Currículo sem Fronteiras, v. 17, n. 2, p. 343-358, maio/ago. 2017.

CASTRO, R. C. L. de. Integração constituinte dos países do MERCOSUL por meio da educação superior Universitária. Análise em uma perspectiva histórico-cultural. Tese de Doutorado. Universidade de São Paulo (USP). 2013.

CELLARD, A. A análise documental. In: POUPART, J.; DESLAURIERS, J. P.; GROULX, L. (Orgs.). A pesquisa qualitativa: enfoques epistemológicos e metodológicos. Petrópolis: Vozes, p. 295-334, 2008.

CURY, C. R. J., A Educação Básica no Brasil. Ed. e Soc., Campinas. n. 80, p. 168-200, setembro. 2002.

DUARTE, R. Entrevistas em pesquisas qualitativas. Educar em Revista, Curitiba, v. 24, p. 213-225, 2004.

DRAIBE, S. M. Coesão social e integração regional: a agenda social do Mercosul e os grandes desafios das políticas sociais integradas. In: Cadernos de Saúde Pública, São Paulo, v. 23, p. 174-183, 2007. 
FERNANDES, E. A. Experiências Linguísticas: como se faz a educação bilíngue com implementação da metodologia do Projeto Escola Intercultural Bilíngue de Fronteira na fronteira entre Brasil e Paraguai. Dissertação de Mestrado, FACALE /UFGD. 2013.

FRIGOTTO, G.; CIAVATTA, M. Educação básica no Brasil na década de 1990: subordinação ativa e consentida à lógica do mercado. Educ. Soc. vol. 24, n. 82. 2003.

FRIZZERA, G. A suspensão do Paraguai no MERCOSUL: problema interno, solução externa. Conjuntura Global, Curitiba, Vol. 2, n. 3, jul./set., 2013.

LORENZONI, I. Programa intercultural terá mais países, cidades e idiomas. In: BRASIL. Ministério da Educação. Escola de Fronteira. Publicado em: 05 nov. 2013. Disponível em: $\mathrm{http} / / /$ portal.mec.gov.br/index.php?option=com_content\&view $=$ article\&id=19218. Acesso em: 13 dez. 2017.

MATO GROSSO DO SUL. Secretaria de Estado de Desenvolvimento Agrário, da Produção, da Indústria, do Comércio e do Turismo (SEPROTUR). Plano de Desenvolvimento e Integração da Faixa de Fronteira/MS. Núcleo Regional para o Desenvolvimento e Integração da Faixa de Fronteira do Estado de Mato Grosso do Sul. Campo Grande, 2012.

MOREIRA, M. A. Aprendizagem significativa em mapas conceituais. Porto Alegre: UFRGS, Instituto de Física, 2013.

NIBUHR, A. N.; ENNS, M. W. La reforma del Estado Paraguaio: Descentralización Política Y Administrativa [Dissertação de mestrado]. Assunción: Universidade Nacional de Asunción; 1996.

PARAGUAI, Ley General de Educación n. 1.264/1998. Disponível em: http://www.une.edu.py/web/images/pdf/Ley1264.PDF. Acesso em: 29 jul. 2017.

RICHARDSON, R. et al. Pesquisa social: métodos e técnicas. 3 ed. 8 reimpr., São Paulo: Atlas, 2008.

RIVAROLA, D. La Reforma Educativa en el Paraguay, Santiago, CEPAL-ECLAC, Serie Políticas Sociales, n. 40, 2000.

ROESLER, P. S. A reforma do sistema educacional paraguaio de 1994. X ANPED SUL, Florianópolis, outubro de 2014.

SILVA, C. P.; TORCHI, G. da F. C. Escolas interculturais de fronteira: um espaço intercultural e mestiço. Revista Geo Pantanal. UFMS/AGB. Corumbá/MS. n. 21. Jul./Dez. 2016.

STURZA, E. R. Das experiências e dos aprendizados no Programa Escolas Interculturais de Fronteiras. In: BRASIL, TV Escola. Salto para o Futuro. Escolas Interculturais de Fronteira. Ano XXIV - Boletim 1. Maio 2014. 
TORCHI, G. da F. C.; SILVA, C. P. da. A expansão do Programa Escolas Interculturais de Fronteira no Estado de Mato Grosso do Sul. Revista GeoPantanal, n. 17, p. 33-46, jul./dez. Corumbá/MS, 2014.

TORCHI, G. da F. C. SILVA, C. P. da. O retrato da fronteira Sul-Mato-Grossense por meio da expansão do Programa Escola Interculturais de Fronteira. In: PINTO, A. C. T.; SILVA, M. R. da. Programa Escola Interculturais de Fronteira (PEIF): 10 anos. Tubarão: Copiart, 2016.

VIZENTINI, P. G. F. O Brasil, o Mercosul e a integração da América do Sul. Revista de Estudos e Pesquisas sobre as Américas, v. 1, n. 1, ago./dez. 2007.

\section{Como referenciar este artigo}

BUENO, M. L. M. C. Configurações na fronteira entre Brasil/Paraguai e a organização do Programa Escolas Interculturais de Fronteira (PEIF). Revista Ibero-Americana de Estudos em Educação, Araraquara, v. 14, n. esp. 3, p. 1702-1716, out., 2019. e-ISSN: 1982-5587. DOI: 10.21723/riaee.v14iesp.3.12755

Submetido em: 25/03/2019

Revisões requeridas: 20/04/2019

Aceito em: 16/06/2019

Publicado em: 30/08/2019 